\title{
Refining Kinetics of Selected Elements in the Industrial Silicon Process
}

\author{
IDA KERO, MARI K. NÆSS, VEGAR ANDERSEN, and GABRIELLA M. TRANELL
}

\begin{abstract}
An industrial oxidative ladle refining process of metallurgical grade silicon has been experimentally examined. An extensive industrial sampling campaign has been performed and samples of silicon and slag have been analyzed by inductively coupled plasma mass spectroscopy (ICP-MS). The elemental concentrations of 45 elements have been evaluated with respect to sampling time during the refining process. Major elements, such as $\mathrm{Ca}$ and $\mathrm{Al}$, as well as trace elements are studied. The refining kinetics is discussed and groups of elements with different behaviors are distinguished. For 21 elements, which are responsive to the refining process, kinetic parameters are established. The alkaline and alkaline earth elements are identified as having the highest refining rates, whereas the rare earth elements are slower and most transition metals are quite unresponsive to the oxidative refining operation.
\end{abstract}

DOI: $10.1007 / \mathrm{s} 11663-015-0305-2$

(C) The Author(s) 2015. This article is published with open access at Springerlink.com

\section{INTRODUCTION}

Metallurgical Grade silicon (MG-Si) ( $>96 \mathrm{wt}$ pct $\mathrm{Si}$ ) is used in a wide variety of processes and products; the main areas of applications ${ }^{11}$ are as alloying agent (e.g., in aluminum alloys), as raw material in chemical industries (e.g., silicone production) and as raw material for higher purity silicon alloys, most notably photovoltaic and electronic grades.

The industrial production route for MG-Si involves carbothermic reduction of quartz in an electric furnace, followed by an oxidative ladle refining (OLR) process. The alloy is tapped into the ladle directly from the electric furnace. The primary purpose of the OLR is to reduce the concentration of $\mathrm{Ca}, \mathrm{Al}$, and other stable, oxide-forming impurities in the silicon alloy. The silicon melt is purged by an air-oxygen mixture, aiming to oxidize the impurities into a slag phase. ${ }^{[1]}$ This silicon OLR process has generic features in common with oxidative refining processes for other metals, for example the more widely studied BOF steelmaking process. ${ }^{[2-5]}$ The thermochemistry of slag and metal phases in the Si refining ladle has been described, mainly with respect to the effect of oxygen potential and the composition/basicity of the slag. ${ }^{[-9]}$

MG-Si contains impurities originating primarily from the carbon-based raw material used for the

IDA KERO, Research Scientist, and MARI K. NÆSS, Post-Doc, are with the Department of Materials Science and Engineering, Norwegian University of Science and Technology, Alfred Getz vei 2, NO-7491, Trondheim, Norway, and also with the SINTEF Materials and Chemistry, Alfred Getz vei 2, Postboks 4760, NO-7465, Trondheim, Norway. Contact e-mail: ida.kero@sintef.no VEGAR ANDERSEN, R\&D Engineer, is with the Elkem AS Silicon Materials, Alfred Getz vei 2, NO-7465, Trondheim, Norway. GABRIELLA M. TRANELL, Professor, is with the Department of Materials Science and Engineering, Norwegian University of Science and Technology.

Manuscript submitted April 8, 2014.

Article published online February 25, 2015. carbothermic reduction, but also from the quartz itself and even from the electrodes heating the furnace. Controlling these impurities may be very important, depending on the intended application for the silicon produced. The main impurities, $\mathrm{Fe}, \mathrm{Al}$, and $\mathrm{Ca}$ form different intermetallic phases with silicon as it solidifies, the types determined by the amounts and ratios of the impurities. ${ }^{[10,11]}$ Trace elements are distributed differently in these intermetallic phases and the effect of these intermetallic phases vary from inert to strongly catalytic, or even directly harmful in the customer processes. ${ }^{[12,13]}$ It is therefore becoming increasingly important to understand how to control the distribution of impurities and trace elements in MG-Si. A number of impurity elements have been evaluated and the difficulties associated with the removal of boron and phosphorus in silicon refining have been widely discussed and studied. ${ }^{[14-18]} \mathrm{We}$ have, in previous publications, reported on the origin and distribution of trace elements in the ladle as well as the elemental composition of the diffuse emissions and silica fume generation during the OLR process. ${ }^{[19-21]}$ The origin and distribution of different impurities and trace elements in the furnace process has been studied and reported by Myrhaug and Tveit. ${ }^{[22]}$

Most investigations in the field of oxidative silicon refining are primarily concerned with the refining of $\mathrm{B}$ and $\mathrm{P}$, due to their crucial importance to photovoltaic silicon applications, and practical measurements are typically carried out in lab-scale experiments. However, kinetic data for other elements are scarce and the fundamental element transport mechanisms and rates in the complex, large-scale industrial silicon refining process have to date not been described in the open literature. The aim of this paper is to describe the behavior of selected minor and trace elements in an industrial OLR process and to extract kinetic data, which can be useful in modeling applications. 


\section{THE REFINING PROCESS}

When silicon is tapped from the furnace into the ladle, it is accompanied by a small amount of unreacted quartz and slag. Compared to other metal extraction processes using ores with lower major mineral content, primary silicon production is considered to be "slag free" with typical oxide amounts in the order of tens of kilos per ton tapped Si. The tapping of the furnace is most often a continuous process; each ladle is immediately replaced by another when it is full. The refining starts right away, as the silicon enters the ladle and continues until the ladle is full and subsequently cast into molds. A mixture of air and oxygen is introduced through a nozzle in the bottom of the ladle. The flux material (quartz sand and Ca-based compounds) is added to the ladle to adjust the slag composition and related physical and chemical properties, such as viscosity. Cooling material may be added to adjust the temperature of the melt before casting; it consists of fines from the crushing operation and will therefore have approximately the same composition as the refined product.

A simplistic description of the OLR process has been proposed by Ashrafian et al. ${ }^{[23]}$ and is illustrated in Figure 1.

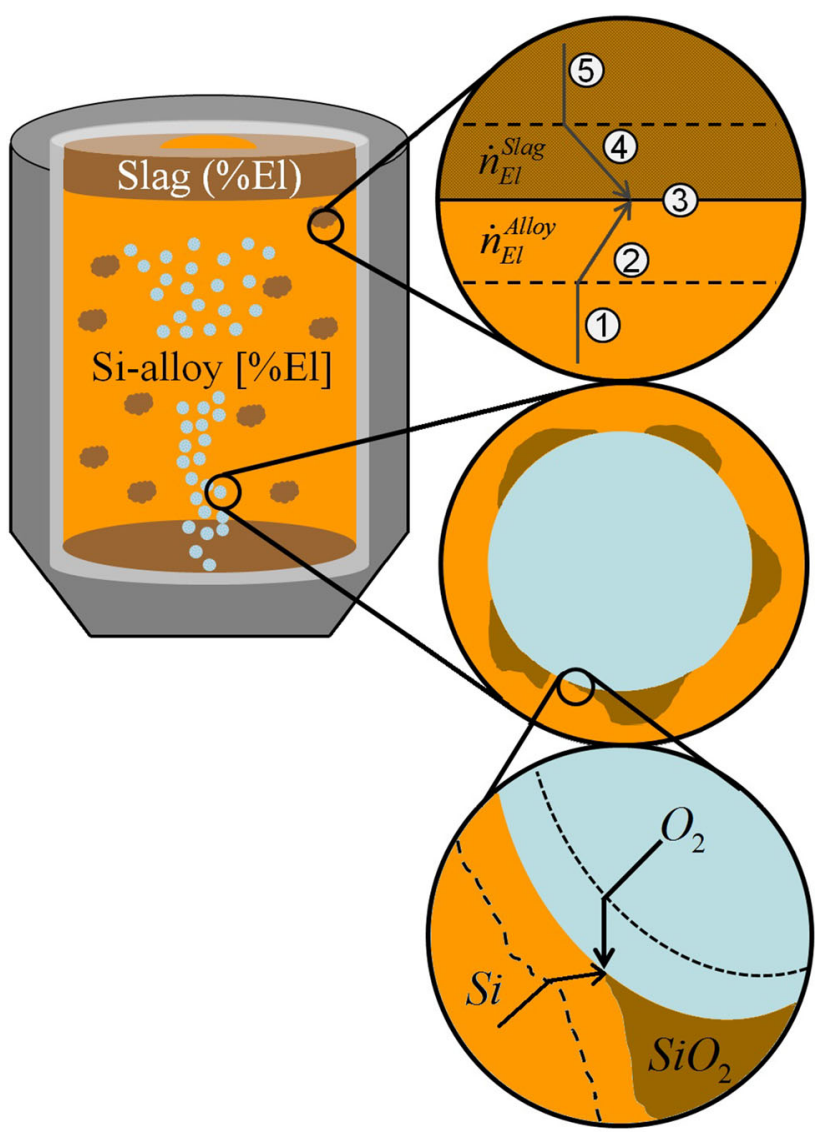

Fig. 1-Schematic of the OLR process with oxygen gas bubbles, top and bottom slag layers and distributed slag droplets, illustrating the boundary layers and interfaces between the silicon alloy and the slag in a refining ladle.
Oxygen in the refining gas will react instantaneously with the liquid silicon and by the time the bubble reaches the top of the ladle, the oxygen has been consumed. Thus, a silica layer forms at the gas bubble/melt interface via the reaction:

$$
\mathrm{Si}_{(1)}+\mathrm{O}_{2(\mathrm{~g})} \rightarrow \mathrm{SiO}_{2(1 / \mathrm{s})}
$$

Silica will also be formed as the silicon from the tap jet hits the silicon in the ladle, dragging air with it into the ladle. The silica produced via both reactions will further react with the main impurities, aluminum and calcium, via the exchange reactions:

$$
\begin{gathered}
4 \mathrm{Al}+3 \mathrm{SiO}_{2} \leftrightarrow 3 \mathrm{Si}+2 \mathrm{Al}_{2} \mathrm{O}_{3} \\
2 \mathrm{Ca}+\mathrm{SiO}_{2} \leftrightarrow \mathrm{Si}+2 \mathrm{CaO} .
\end{gathered}
$$

The exchange reaction between the two main impurities in the ternary $\mathrm{SiO}_{2}-\mathrm{CaO}-\mathrm{Al}_{2} \mathrm{O}_{3}$ slag can be described as

$$
3 \underline{\mathrm{Ca}}+\mathrm{Al}_{2} \mathrm{O}_{3} \leftrightarrow 2 \underline{\mathrm{Al}}+3 \mathrm{CaO} .
$$

Based on industrial observations and the modeling work of Ashrafian ${ }^{[24]}$ for the interfacial and physical properties of the slag film formed at the bubble/metal interface, it is likely that the slag formed on the bubble surfaces does not wet the surface completely but detach from the bubbles and mix with the silicon. The difference in density between silicon alloy and slag is small so the slag droplets will be readily dispersed in the liquid silicon. ${ }^{[1]}$

Although the slag, due to the initial concentration of $\mathrm{Ca}$ and $\mathrm{Al}$ in the metal, is dominated by the ternary $\mathrm{SiO}_{2}-\mathrm{CaO}-\mathrm{Al}_{2} \mathrm{O}_{3}$ system, other impurities take part in the metal-slag mass exchange. Oxidation of an element El dissolved in silicon can be expressed by the reaction:

$$
\frac{x}{y} \underline{\mathrm{El}}+\frac{y}{2} \mathrm{O}_{2}=\frac{1}{y} \mathrm{El}_{x} \mathrm{O}_{y} \text {. }
$$

The first slag formed is high in $\mathrm{CaO}$ and subsequently in $\mathrm{Al}_{2} \mathrm{O}_{3}$ and its density is somewhat higher than that of the Si melt. ${ }^{[1]}$ As the refining cycle progresses, the slag, often aided by fluxing, will change in composition and a slag with higher $\mathrm{SiO}_{2}$ content and lower density will form at the top of the ladle toward the end of the cycle (from here on called top slag). As the purging of the gas stirs the melt, the top slag is pushed toward the periphery of the ladle, forming a ring, which leaves the $\mathrm{Si}$ in the center exposed to air. Liquid silicon stirred by the bubbling will be trapped with this top slag crust. As the ladle is poured, the free flowing slag formed during refining will adhere to the ladle walls and bottom (from here on called bottom slag). A "top-to-bottom" ratio (TBR) has been used in the current work to evaluate how the elements distribute themselves between the topand bottom slags. Elements with TBR $>1.5$ are here defined as mainly found in the top slag, whereas elements with TBR $<0.5$ are mainly found in the 
bottom slag. Elements with TBR between 0.5 and 1.5 are considered to be distributed fairly equal between the two slag types.

$$
\mathrm{TBR}=\frac{(\mathrm{El})_{\mathrm{top}}}{(\mathrm{El})_{\text {bottom }}}
$$

The efficiency of the slag refining process is given by the reduction of impurities in the silicon alloy, and the equilibrium distribution of elements between metal and slag will be determined by thermochemical constraints. The refining efficiency is commonly quantified by the ratio of the concentrations of elements between the slag and the silicon. At equilibrium, the distribution of an element between slag and metal is expressed as

$$
L_{\mathrm{El}}=\frac{(\mathrm{El})}{[\mathrm{El}]},
$$

where $L_{\mathrm{El}}$ is the distribution coefficient for an element, $\mathrm{El}$, (El) is the concentration by weight of the element in the slag, and [El] is the concentration by weight of the element in the molten silicon.

The relative removal rate of an impurity element from the silicon alloy is determined by process parameters and the elements behavior in the given metal and slag environment. As schematically illustrated in Figure 1, the transport of a dissolved element from metal to slag/ oxide at a metal/slag or bubble/silicon interface includes 5 potential rate-determining steps: ${ }^{[25]}$

1. The impurity element is transferred from the liquid bulk phase to the silicon boundary layer.

2. The element diffuses through the silicon boundary layer.

3. The impurity is oxidized at the interface between silicon alloy and slag.

4. The impurity element oxide diffuses through the slag boundary layer.

5. The impurity oxide is transferred from the slag boundary layer to slag bulk phase.

Which of these steps is rate limiting is determined by the properties of the slag and alloy, as well as the degree of mixing/fluid flow of phases in the system. This may also change throughout the refining cycle. Gas stirring and small differences in densities provide good conditions for good mixing between the (bottom) slag and metal phases. Thus, the transport of elements in the bulk phases (step 1 and 5) should not be limited by concentration gradient-driven diffusion, in either of the bulk phases. In reality, however, the viscosity or melting temperature of the slag/oxide may make mixing and transport difficult.

Due to the high temperature of the system, it is generally assumed that the chemical oxidation reactions in step 3 (Eqs. [1] through [5]) will approach local equilibrium relatively fast ${ }^{[9]}$ and are not likely to be rate limiting for the refining efficiency.

The transports of an element through the silicon and slag boundary layers depend on convection and diffusion. The mass transfer coefficients in slag and metal boundary layers, $k_{S}$ and $k_{M}$, depend on the thickness of the boundary layers, and the diffusivity of the element and its corresponding oxide. The individual mass transfer coefficients for the slag and alloy boundary layers may differ greatly, often by orders of magnitude. As such, the resistance in the metal boundary layer may often be disregarded and the total mass transfer coefficient approximated with the mass transfer coefficient in the slag boundary layer. The respective resistances in the boundary layers are summed up and replaced with a total mass transfer coefficient, $k_{\mathrm{t}}$.

As described above, in the OLR process, metal is continuously tapped into the ladle and new slag formed by the oxidative gas blowing. However, the metal/slag ratio remains reasonably constant. For elements in dilute solution, the activity coefficients of elements and compounds in the metal and slag remain approximately constant. This does not apply for $\mathrm{Ca}$ and $\mathrm{Al}$ in the slag phase as these are present in higher concentrations than other elements in silicon and are thus major components in the slag formed. Meanwhile, the contact area between metal and slag, as well as the total mass of metal in the ladle change with time - the contact area as a function of density and viscosity of the slag and the mass of metal, as a function of furnace tapping rate.

In order to numerically describe the OLR process, given the above considerations, we may, however, start by a batch-like representation of the rate of transfer of an element, El from the metal to slag according to ${ }^{[9]}$

$$
\begin{gathered}
\int_{[\mathrm{El}]_{\mathrm{in}}}^{[\mathrm{El}]} \frac{\mathrm{d}[\mathrm{El}]}{[\mathrm{El}]-[\mathrm{El}]_{\mathrm{eq}}}=-\int_{0}^{t} \frac{k_{t} \rho A_{\mathrm{s}}}{M}\left(1+\frac{\gamma_{\mathrm{El}}}{f_{\mathrm{El}} K} \frac{M}{M_{\mathrm{S}}}\right) \mathrm{d} t \quad[8] \\
\frac{[\mathrm{El}]-[\mathrm{El}]_{\mathrm{eq}}}{[\mathrm{El}]_{\mathrm{in}}-[\mathrm{El}]_{\mathrm{eq}}}=\exp \left(-\frac{k_{t} \rho A_{\mathrm{s}} t}{M}\left(1+\frac{\gamma_{\mathrm{El}}}{f_{\mathrm{El}} K M_{\mathrm{s}}}\right)\right)=\exp \left(-\frac{t}{\tau}\right),
\end{gathered}
$$

where

$$
\tau=\frac{M}{k_{t} \rho A_{\mathrm{S}}\left(1+\frac{\gamma_{\mathrm{El}} M}{f_{\mathrm{El}} K M_{\mathrm{s}}}\right)},
$$

where $\rho$ is the density of the alloy, and $A_{\mathrm{s}}$ is the area of the interface between alloy and slag. $M$ and $M_{\mathrm{s}}$ are the mass of the alloy and slag, respectively, $\gamma_{E l}$ is the Raoultian activity coefficient of the element oxide in the slag phase, and $f_{\mathrm{El}}$ is the Henrian activity coefficient of the element in the silicon alloy. $K$ is the equilibrium constant for Eq. [5], $\tau$ is a time parameter describing the refining kinetics for an element ( $t=\tau$ when the difference between the concentration of an element $[\mathrm{El}]$ and $[\mathrm{El}]_{\mathrm{eq}}$ is reduced to $1 /$ $e=0.37$ of the difference at $t=0$ ) and is dependent on temperature and ladle geometry (affecting the mass transfer coefficient $k_{t}$ ). If the dimension of the kinetic parameter $\tau$ is determined for different elements under the same process conditions, the relative rate of refining for individual elements may be established.

As pointed out above, Eqs. [8] through [10] describe kinetics of silicon refining in a batch process. In the 
industrial process under consideration here, the refining is performed during tapping, i.e., a semi-continuous process. However, the parameters in Eq. [8]- $M, M_{\mathrm{s}}, \rho$, and $A_{\mathrm{s}}$-are all functions of time and change in the same manner for all elements. This allows a comparison of refining kinetics for different elements based on Eqs. [8] through [10]. Accordingly, the normalized $\tau$, will constitute a crude approximation for this type of process. In a normalized, general expression, the refining can be expressed as

$$
\frac{\operatorname{Norm}[\mathrm{El}]-\operatorname{Norm}[\mathrm{El}]_{\mathrm{eq}}}{\operatorname{Norm}[\mathrm{El}]_{\mathrm{in}}-\operatorname{Norm}[\mathrm{El}]_{\mathrm{eq}}}=\exp \left(-\frac{t}{\operatorname{Norm} \tau}\right),
$$

where

$$
\text { Norm } \tau=\frac{1}{k_{t}\left(1+\frac{\gamma_{\mathrm{El}}}{f_{\mathrm{El}} K}\right)}
$$

In this expression, the normalized $\tau$ is a function of a kinetic term; the total mass transfer coefficient $k_{t}$, and a thermodynamic driving force term; the activity coefficients and equilibrium constants $\left(\frac{\gamma_{\mathrm{El}}}{f_{\mathrm{EI}} K}\right)$ for the refining of the element in question. These equations will be used to compare refining kinetics for different elements in silicon.

\section{METHOD}

\section{A. Experimental Procedure}

A comprehensive industrial measurement campaign was performed at an MG-Si plant with a $35 \mathrm{MW}$ furnace which produces 25,000 tons of high-silicon alloy per year. Samples of silicon and slag were taken, as illustrated in Figure 2 from eight different refining ladles with standard purge gas mixture and flow rate conditions during three days.

At the time of the sampling, the temperature in the $\mathrm{Si}$ was in the range of $1719 \mathrm{~K}$ to $1950 \mathrm{~K}\left(1446{ }^{\circ} \mathrm{C}\right.$ to $1677^{\circ} \mathrm{C}$ ). Samples from the unrefined $\mathrm{Si}$, as tapped into the ladle, were taken from the tapping jet. Samples of liquid Si were collected when the ladle had been filled by

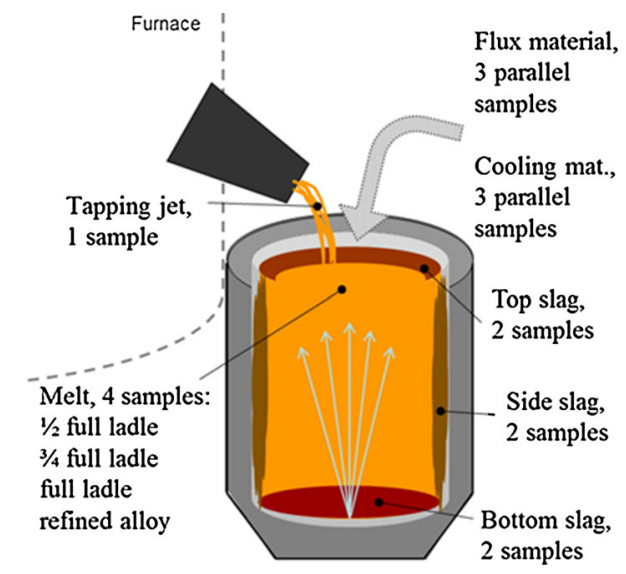

Fig. 2-Sketch of the oxidative ladle refinement process and the samples collected. half, by three quarters and completely. Finally, a sample of the refined $\mathrm{Si}$ was collected just before casting. Sampling times and conditions are detailed in Table I. Slag samples were taken from the top and bottom slags after the Si had been removed from the ladle by the casting operation. A "top-to-bottom ratio" (TBR), as defined by Eq. [6], was calculated based on these results.

Three samples were also taken from each of the storage rooms for cooling and flux materials, respectively. The samples were all analyzed by HR-ICP-MS. The solid bulk samples were crushed to a powder and all samples were dissolved in acids prior to ICP-MS analysis. The sampling procedure and error sources (including inhomogeneity estimations), as well as element distribution between phases have been described in greater detail elsewhere. ${ }^{[19,20]}$

\section{B. Establishing Kinetic Parameters}

The experimentally obtained element concentrations were used to estimate numerical values for the kinetic parameters of 21 elements which responded to the refining treatment in the OLR process. Regression lines were fitted to the experimental data, and the kinetic parameter $\tau$ was deduced from the regression lines by means of the least squares optimization method. An alternative numerical iteration method was also used to fit the experimental data to a mathematical description which allowed time variations of the silicon and slag masses (in principle a semi-continuous approach). This approach was tried for $\mathrm{Al}$ and the results were compared to the batch description. While the numerical approach is theoretically more correct, it is also more complex and time consuming, and the results were not significantly better than what could be generated by the simpler batch description. The variation between the two models was within the variations caused by process variations in the experimental data. Therefore, the batch model was chosen for further kinetic evaluation.

For elements with thermodynamic data available in the literature $e^{[1,26-28]}(\mathrm{Ca}, \mathrm{Al}, \mathrm{Mg})$, equilibrium concentrations were compared to the experimental values of the refined samples and found to be in the same order of magnitude. Hence, for simplicity, the equilibrium concentration values $\left([\mathrm{El}]_{\mathrm{eq}}\right)$ were set to the experimentally obtained values for the refined product $\left(\mathrm{C}_{\mathrm{ref}}\right)$. All reported concentrations in this work have been normalized to the tapping concentration of each ladle and element. The concentration ranges in the refined alloy $\left(\mathrm{C}_{\mathrm{ref}}\right)$ as well as the normalized equilibrium concentration values (Norm[El $]_{\mathrm{eq}}$ ) used in the regression are given in Table II.

\section{RESULTS AND DISCUSSION}

In this section, we have chosen to show the data from only a few of the elements included in this study. The elements are however chosen because they are representative and exemplify the typical behaviors of many elements in the ladles. 
Table I. Overview of Samples Taken and Their Respective Conditions

\begin{tabular}{llr}
\hline Sample & \multicolumn{1}{c}{ Sample Collected } & $T$ in melt, ${ }^{\circ} \mathrm{C}$ \\
\hline Unrefined Si & from jet, early in the tapping process & 1551 to 1677 \\
$\mathrm{Si}, 50$ pct & when ladle is half full & 1551 to 1677 \\
$\mathrm{Si}, 75 \mathrm{pct}$ & when ladle is three quarters full & 1456 to 1549 \\
$\mathrm{Si}, 100 \mathrm{pct}$ & when ladle is full & 1456 to 1549 \\
Refined Si & right before casting & 1446 to 1506 \\
Flux material & from three different bags & ambient \\
Cooling metal & three parallels from the batch & ambient \\
Slags & after casting & N/A \\
\hline
\end{tabular}

Table II. Selected Kinetic and Thermodynamic Parameters. The Activity Coefficients are Evaluated at $1873 \mathrm{~K}\left(1600{ }^{\circ} \mathrm{C}\right)^{[28,29]}$

\begin{tabular}{|c|c|c|c|c|c|c|c|c|c|}
\hline Element & $\tau(\min )$ & Norm $\tau$ & Norm $[\mathrm{El}]_{\mathrm{eq}}$ & $R^{2}$ & $f_{\text {El-Si }}$ & $\operatorname{Norm} \frac{\mathrm{d}[\mathrm{El}]}{\mathrm{d} t}$ & $L_{\mathrm{El}}$ & TBR & $C_{\text {ref }}(\mathrm{ppm})$ \\
\hline Samarium, Sm & 71.5 & 2.2 & 0.43 & 0.47 & & 0.0038 & 1.6 & 1.4 & 0.5 to 5 \\
\hline Praseodymium, $\mathrm{Pr}$ & 68.1 & 2.1 & 0.62 & 0.35 & & 0.0029 & 0.43 & 3.5 & 1 to 5 \\
\hline Cerium, $\mathrm{Ce}$ & 67.4 & 2.0 & 0.60 & 0.38 & & 0.0031 & 0.48 & 3.7 & 10 to 50 \\
\hline Neodymium, Nd & 67.2 & 2.0 & 0.62 & 0.37 & & 0.0030 & 0.45 & 3.1 & 5 to 50 \\
\hline Lanthanum, La & 66.0 & 2.0 & 0.39 & 0.51 & & 0.0046 & 0.59 & 2.5 & 5 to 50 \\
\hline Ytterbium, Yb & 60.2 & 1.8 & 0.19 & 0.73 & & 0.0074 & 5.1 & 0.33 & 0.1 to 1 \\
\hline Dysprosium, Dy & 58.9 & 1.8 & 0.46 & 0.52 & & 0.0049 & 1.3 & 0.89 & 0.5 to 5 \\
\hline Terbium, $\mathrm{Tb}$ & 58.9 & 1.8 & 0.51 & 0.43 & & 0.0043 & 0.96 & 1.2 & 0.1 to 0.5 \\
\hline Aluminum, $\mathrm{Al}$ & 58.0 & 1.8 & 0.17 & 0.86 & 0.45 & 0.0072 & 6.4 & 0.31 & $1 \times 10^{3}$ to $5 \times 10^{3}$ \\
\hline Holmium, Ho & 57.9 & 1.8 & 0.38 & 0.57 & & 0.0057 & 1.7 & 0.71 & 0.1 to 0.5 \\
\hline Thulium, Tm & 57.4 & 1.7 & 0.30 & 0.67 & & 0.0068 & 2.8 & 0.48 & 0.05 to 0.5 \\
\hline Erbium, Er & 57.2 & 1.7 & 0.34 & 0.62 & & 0.0063 & 2.2 & 0.59 & 0.1 to 5 \\
\hline Scandium, Sc & 56.6 & 1.7 & 0.48 & 0.60 & & 0.0052 & 0.88 & 0.65 & 1 to 5 \\
\hline Lutetium, Lu & 55.4 & 1.7 & 0.21 & 0.77 & & 0.0083 & 5.0 & 0.33 & 0.01 to 0.1 \\
\hline Yttrium, Y & 53.5 & 1.6 & 0.16 & 0.77 & $5.7 \times 10^{-5}$ & 0.0090 & 5.0 & 0.42 & 0.5 to 10 \\
\hline Magnesium, $\mathrm{Mg}$ & 42.8 & 1.3 & 0.16 & 0.94 & 0.28 & 0.011 & 7.1 & 0.80 & 1 to 10 \\
\hline Lithium, Li & 37.9 & 1.1 & 0.050 & 0.93 & 0.017 & 0.012 & 122 & 0.12 & 0.05 to 0.5 \\
\hline Beryllium, Be & 37.7 & 1.1 & 0.054 & 0.88 & & 0.013 & 196 & 0.11 & 0.01 to 0.5 \\
\hline Calcium, $\mathrm{Ca}$ & 33.6 & 1.0 & 0.017 & 0.82 & $4.1 \times 10^{-3}$ & 0.014 & 149 & 0.19 & 10 to 100 \\
\hline Strontium, $\mathrm{Sr}$ & 33.1 & 1.0 & 0.0076 & 0.78 & & 0.015 & 233 & 0.24 & $<5$ \\
\hline Barium, $\mathrm{Ba}$ & 33.0 & 1.0 & 0.0094 & 0.83 & & 0.014 & 295 & 0.13 & $<5$ \\
\hline
\end{tabular}

Norm $\tau$ values are normalized based on $\tau$ for Ba.

\section{A. Element Behavior in the Ladle, Reproducibility and Reliability of Industrial Data}

Three groups of elements were distinguished based on their behavior in the OLR process: elements readily refined in the ladle (21 elements: $\mathrm{Al}, \mathrm{Ba}, \mathrm{Be}, \mathrm{Ca}, \mathrm{Ce}, \mathrm{Dy}$, Er, Ho, La, Li, Lu, Mg, Nd, Pr, Sm, Sc, Sr, Tb, Tm, Yb, $\mathrm{Y})$, elements which do not respond to the refining process (19 elements: B, Co, Cr, Cu, Fe, Ge, Hf, Mn, Mo, Nb, Ni, $\mathrm{Pt}, \mathrm{P}, \mathrm{Ta}, \mathrm{Ti}, \mathrm{Th}, \mathrm{U}, \mathrm{V}, \mathrm{W}, \mathrm{Zr}$ ), and elements which are added by the flux material ( 5 elements: $\mathrm{As}, \mathrm{Ga}, \mathrm{Pb}, \mathrm{Sn}$, and $\mathrm{Zn})$. Figures 3, 4, and 5 show the elemental concentrations of $\mathrm{Pb}, \mathrm{Ti}$, and $\mathrm{La}$, respectively, as functions of time. These three elements represents the three groups; La represents those which are readily refined; Ti represents those which do not respond to the refining process; and $\mathrm{Pb}$ represents those which do respond to the slag refining treatment to some extent but are significantly added to the melt by the flux material.

The time for adding the flux and the amount of flux material varies between the ladles; hence the variations in these element concentrations between ladles are generally larger than for other elements. No flux was added to Ladle C.

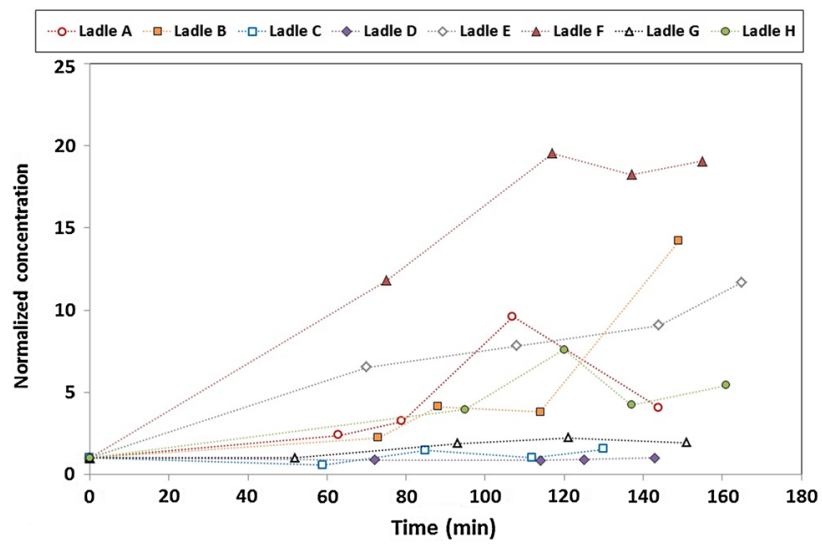

Fig. 3-Normalized $\mathrm{Pb}$ concentration as function of refining time.

$\mathrm{Ti}, \mathrm{Fe}$, and the other transition metals, along with $\mathrm{B}$ and $\mathrm{P}$, are among the elements which do not transfer to the slag to any significant extent. Given these elements' relative redox potential compared to that of silicon, this is expected behavior. The concentration trends of $\mathrm{Fe}$ and $\mathrm{B}$ are given in Figures 6 and 7, respectively. 


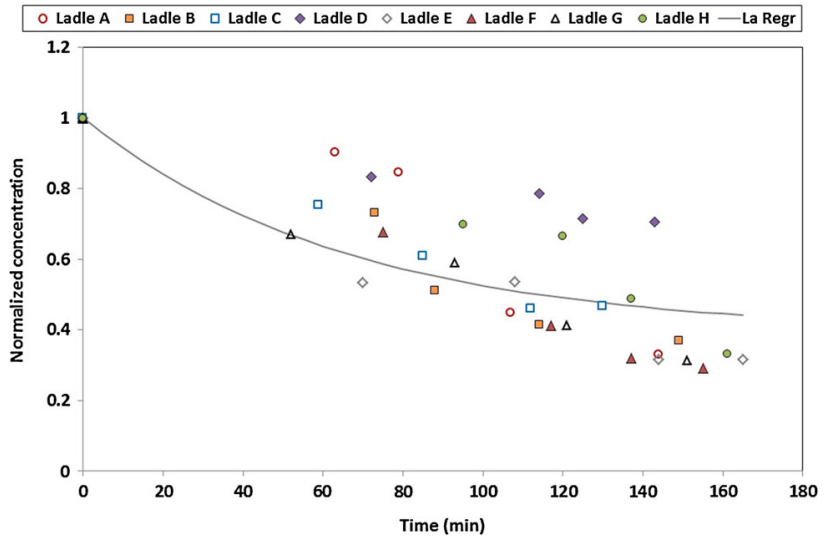

Fig. 4-Normalized La concentration as function of time.

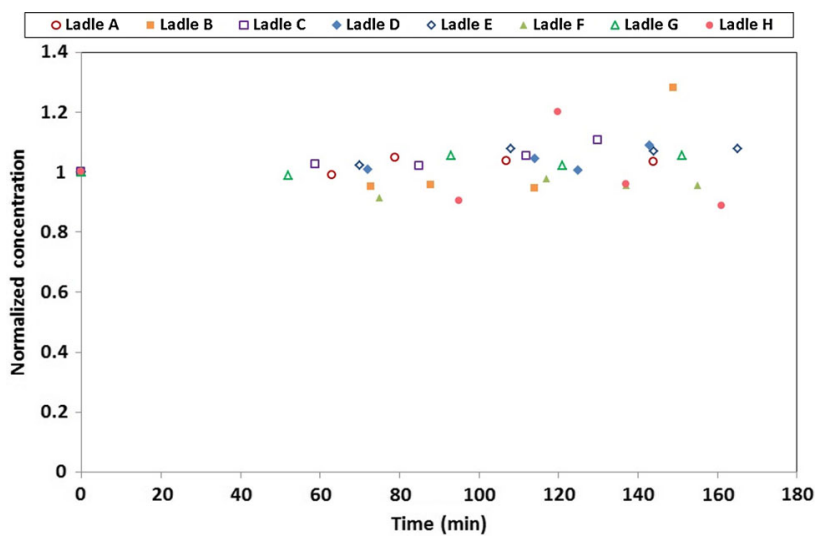

Fig. 5-Normalized Ti concentration as function of refining time.

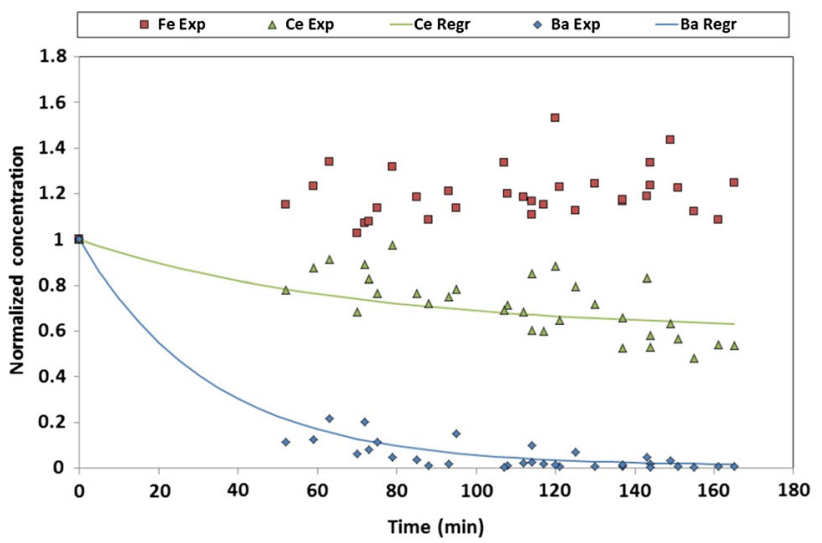

Fig. 6-Normalized $\mathrm{Fe}, \mathrm{Ce}$, and $\mathrm{Ba}$ concentrations as functions of refining time.

As the experimental data were obtained from a real industrial process, the scatter of the data is indicative of both the process variations and experimental errors. The concentrations have been normalized to the tapping concentration of each ladle and the final concentrations are in the ranges of $0.01-0.5 \mathrm{ppm}, 500-1000 \mathrm{ppm}$, and 5-50 ppm for $\mathrm{Pb}, \mathrm{La}$, and $\mathrm{Ti}$, respectively. The concentration intervals for the elements in this study have been previously reported ${ }^{[19]}$ and for the elements that are refined from the metal, these values are also listed in Table II $\left(\mathrm{C}_{\mathrm{ref}}\right)$. The error sources and uncertainties of the industrial measurements as well as the subsequent data analysis have also been thoroughly investigated and reported. ${ }^{[20]}$ The $R^{2}$ values of the regression lines are shown in Table II. As seen from the figures, the refining trends are consistent and reproducible between ladles for each element within the uncertainty limits. Also trace elements, present at low concentrations, exhibit similar trends and kinetic relations which appear to be constant within their respective concentration intervals. $R^{2}$ values are fair ( $>0.6$ ) for most elements, with some exceptions, considering the industrial origin of these data.

In Figure 6, $\mathrm{Ce}$ and $\mathrm{Ba}$ represent the readily refined elements with slow and fast refining rates, respectively. This group also includes the major slag-forming elements $\mathrm{Ca}, \mathrm{Al}$, and $\mathrm{Mg}$ whose refining regression curves are shown in Figure 7.

\section{B. Refining Kinetics}

The refining kinetics has been evaluated for the 21 readily refined elements and in Table II, the elements have been listed in order of their respective determined $\tau$ values (based on regression of the experimental data). The refined slag-metal distributions of these elements $\left(\mathrm{L}_{\mathrm{El}}\right)$ are also tabulated; these values are based on the average values of top, side, and bottom slags yet the same trend is seen if only the bottom slag concentrations are used. The normalized $\tau$ (Norm $\tau$ ), the normalized element equilibrium concentration (Norm $[\mathrm{El}]_{\mathrm{eq}}$ ), and the normalized initial refining rate (Norm $\mathrm{d}[\mathrm{El}] / \mathrm{d} t$ ) are given in Table II. The actual element concentration ranges in the refined silicon $\left(\mathrm{C}_{\mathrm{ref}}\right)$ are also included in the table, represented by relatively wide intervals as they are set to include the industrial variations as well as estimated errors. The numbers still indicate the order of magnitude for the concentrations of the different elements. ${ }^{[20]}$

As illustrated by the periodic system in Figure 8 (and the data in Table II), three groups of element behavior can be distinguished. The first group includes Groups 1 and 2 elements in the periodic table, $\mathrm{Ba}, \mathrm{Sr}, \mathrm{Ca}, \mathrm{Mg}, \mathrm{Be}$, and $\mathrm{Li}$, all featuring low $\tau$ values (30 to 40 minutes), i.e., high refining rates. These elements, with the exception of $\mathrm{Mg}$, also display significantly higher $L_{\mathrm{El}}$ values $(>100)$ than the other elements.

The second group of elements includes Group 3 elements ( $\mathrm{Lu}, \mathrm{Y}, \mathrm{Sc})$ and the heavy Lanthanoids (Er, $\mathrm{Tm}, \mathrm{Ho}, \mathrm{Dy}, \mathrm{Yb})$ as well as and Al, featuring - with some exceptions - $\tau$ values between 40 and 60 and $L_{\mathrm{El}}$ values between approximately 1 and 7 .

The last group includes the light lanthanoids $(\mathrm{La}, \mathrm{Nd}$, $\mathrm{Ce}, \mathrm{Pr}$, and $\mathrm{Sm}$ ) with $\tau$ values typically between 60 and 70 and associated $L_{\mathrm{El}}$ values below unity. The $R^{2}$ values of the regression lines in the last group are generally lower than the other groups, trends are therefore considered less reliable, and the industrial process variation is considerably higher for these elements.

Also considering the variations in $R^{2}$ values, there are nevertheless distinguishable patterns to element behavior, i.e., elements with higher refining rates have high 
metal-slag distribution $\left(L_{\mathrm{El}}\right)$ values (in particular group 1 and 2 elements) and low normalized equilibrium concentration $\left(\right.$ Norm $\left.[\mathrm{El}]_{\mathrm{eq}}\right)$ values. As activity coefficient data for most exotic elements in silicon are not known, $L_{\mathrm{El}}$ and Norm[El] eq parameters may be used as descriptors of the thermodynamic driving force for oxidation. A large $L_{\mathrm{El}}$ value is indicative of a strong positive deviation from ideality of $\mathrm{El}$ in silicon or a comparatively low activity coefficient of its oxide in the slag formed. In Figure 9, the normalized element removal rate from silicon $(d[E l] / d \mathrm{t})$ of the different elements for the first, linear part of the refining cycle, i.e., the period from $t=0$ to half-full ladle as well as Norm $\tau$, have been plotted as functions of $L_{\mathrm{El}}$ and Norm $[\mathrm{El}]_{\text {eq }}$, respectively. As shown in figure, the refining rate is a logarithmic function of $L_{\mathrm{El}}$ and a linear function of

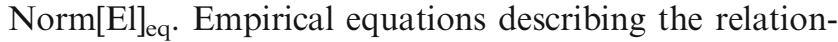
ship between $\mathrm{d}[\mathrm{El}] / \mathrm{d} t$, Norm $\tau$ and $L_{\mathrm{El}}$ and $\operatorname{Norm}[E l]_{\mathrm{eq}}$, respectively, can be extracted from the trend line equations:

$$
\operatorname{Norm} \frac{\mathrm{d}[\mathrm{El}]}{\mathrm{d} t}=0.0017 \ln L_{\mathrm{El}}+0.0048
$$

$$
\text { Norm } \tau=-0.16 \ln \left(L_{\mathrm{El}}\right)+1.9
$$

$$
\operatorname{Norm} \frac{\mathrm{d}[\mathrm{El}]}{\mathrm{d} t}=-0.0018 \operatorname{Norm}[\mathrm{El}]_{\mathrm{eq}}+0.0013
$$

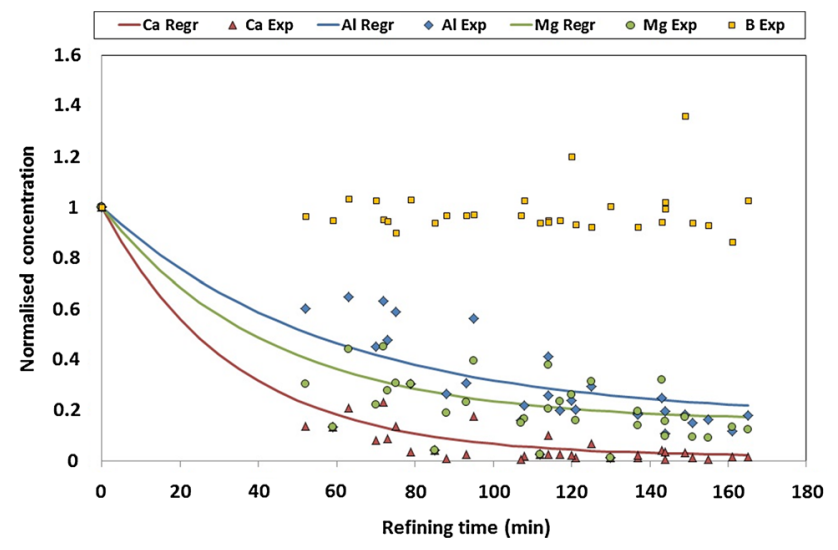

Fig. 7-Normalized $\mathrm{Ca}, \mathrm{Al}, \mathrm{Mg}$, and $\mathrm{B}$ concentrations as function of time.
In Figure 10, the standard Gibbs free energies of formation of element oxides (at $1600{ }^{\circ} \mathrm{C}$ ) are plotted in size order. As seen in figure, there is no direct correlation between the Gibbs free energy of oxide formation and the refining time $\tau$, tabulated in Table II. Since only few of the elements have known values of the activity coefficient in silicon $\left(f_{\mathrm{EL}}\right)$, and the activity of element oxides will vary over the refining cycle as the slag composition changes, it is difficult to directly couple the refining rate to the thermodynamic driving forces. However, it is possible to discuss the relative refining rates of different elements from a starting point in the exchange reaction with $\mathrm{Si} / \mathrm{SiO}_{2}$. As described above, we consider that the first reaction to take place as the liquid silicon meets an oxygen-rich bubble (either in the tapping jet as it hits the silicon in the ladle dragging in oxygen from the atmosphere, or as the refining gas purged through the bottom plug meets the metal in the ladle) is the oxidation of $\mathrm{Si}$ to form $\mathrm{SiO}_{2}$ on the bubble surface. In order to minimize the Gibbs energy of the silica phase, it will react preferentially with elements that form stable oxide solutions with $\mathrm{SiO}_{2}$ in exchange reactions like those shown in Eqs. [2] and [3]. The rapidly refined elements in groups 1 and $2(\mathrm{Ba}, \mathrm{Sr}, \mathrm{Ca}$, $\mathrm{Li}, \mathrm{Be}$, and $\mathrm{Mg}$ ) are basic oxides, which act to reduce the $\mathrm{SiO}_{2}$ activity and form such stable solutions. The optical basicity (a measure of the electron donor power of an oxide or slag relative to $\mathrm{CaO}$ ) recommended by Duffy and Ingram $^{[30]}$ of these oxides follows the same relative order as the, respectively, decreasing $\tau$ and increasing $L_{E l}$ values, ranging from 1.15 for $\mathrm{Ba}$ to 0.78 for $\mathrm{Mg}$. Oxides such as $\mathrm{Al}_{2} \mathrm{O}_{3}$ and the lanthanoids are generally considered amphoteric or acid oxides and while these all have low Gibbs energies of pure oxide formation, they are more slowly refined than their basic counterparts. It is hence reasonable to deduce that the (initial) relative rates of refining for individual elements follow the order in which they serve to minimize the Gibbs energy of the slag/oxide solution formed together with $\mathrm{SiO}_{2}$. Elements forming acidic and amphoteric oxides will likely oxidize predominantly when a relatively basic slag has been formed.

The above discussion of relative refining rates is

\begin{tabular}{|c|c|c|c|c|c|c|c|c|c|c|c|c|c|c|c|c|c|}
\hline $\mathrm{H}$ & \multirow[b]{2}{*}{$\mathrm{Be}$} & & & \multirow{2}{*}{\multicolumn{2}{|c|}{$\begin{array}{l}\tau>50 \\
+L<1\end{array}$}} & \multirow{2}{*}{\multicolumn{2}{|c|}{$\begin{array}{l}\tau>50 \\
+L>1\end{array}$}} & \multirow{2}{*}{\multicolumn{2}{|c|}{$\tau<50$}} & & & \multirow[b]{2}{*}{$B$} & \multirow[b]{2}{*}{ C } & \multirow[b]{2}{*}{$N$} & \multirow[b]{2}{*}{0} & \multirow[b]{2}{*}{$\mathrm{F}$} & $\mathrm{He}$ \\
\hline $\mathrm{Li}$ & & & & & & & & & & & & & & & & & $\mathrm{Ne}$ \\
\hline $\mathrm{Na}$ & $\mathrm{Mg}$ & & & & & & & & & & & Al & Si & $\mathrm{P}$ & $S$ & $\mathrm{Cl}$ & Ar \\
\hline K & $\mathrm{Ca}$ & Sc & $\mathrm{Ti}$ & V & $\mathrm{Cr}$ & & $\mathrm{Fe}$ & $\mathrm{Co}$ & $\mathrm{Ni}$ & $\mathrm{Cu}$ & $\mathrm{Zn}$ & $\mathrm{Ga}$ & $\mathrm{Ge}$ & As & $\mathrm{Se}$ & $\mathrm{Br}$ & $\mathrm{Kr}$ \\
\hline $\mathrm{Rb}$ & $\mathrm{Sr}$ & $Y$ & $\mathrm{Zr}$ & $\mathrm{Nb}$ & $\mathrm{Mc}$ & & $\mathrm{Ru}$ & $\mathrm{Rh}$ & $\mathrm{Pc}$ & $\mathrm{Ag}$ & $\mathrm{Cd}$ & In & $\mathrm{Sn}$ & $\mathrm{Sb}$ & $\mathrm{Te}$ & I & $\mathrm{Xe}$ \\
\hline Cs & $\mathrm{Ba}$ & Lu & $\mathrm{Hf}$ & $\mathrm{Ta}$ & W & & Os & Ir & $\mathrm{Pt}$ & $\mathrm{Au}$ & $\mathrm{Hg}$ & $\mathrm{Tl}$ & $\mathrm{Pb}$ & $\mathrm{Bi}$ & Po & At & $\mathrm{Rn}$ \\
\hline $\mathrm{Fr}$ & $\mathrm{Ra}$ & $\mathrm{Lr}$ & Rf & $\mathrm{Db}$ & $\mathrm{Sg}$ & & $\mathrm{Hs}$ & $\mathrm{Mt}$ & Uu & Uut & Uub & & Uuq & & & & \\
\hline
\end{tabular}
further supported by the measured distribution of elements between bottom and top slags. The top-to-

\begin{tabular}{|c|c|c|c|c|c|c|c|c|c|c|c|c|c|}
\hline La & $\mathrm{Ce}$ & $\mathrm{Pr}$ & $\mathrm{Nd}$ & $\mathrm{Pm}$ & $\mathrm{Sm}$ & $\mathrm{Eu}$ & $\mathrm{Gd}$ & $\mathrm{Tb}$ & $\mathrm{Dy}$ & $\mathrm{Ho}$ & $\mathrm{Er}$ & $\mathrm{Tm}$ & $\mathrm{Yb}$ \\
\hline $\mathrm{Ac}$ & $\mathrm{Th}$ & $\mathrm{Pa}$ & $\mathrm{U}$ & $\mathrm{Np}$ & $\mathrm{Pu}$ & $\mathrm{Am}$ & $\mathrm{Cm}$ & $\mathrm{Bk}$ & $\mathrm{Cf}$ & $\mathrm{Es}$ & $\mathrm{Fm}$ & $\mathrm{Md}$ & $\mathrm{No}$ \\
\hline
\end{tabular}

Fig. 8-The placement of the elements of the three distinguished behavior groups. 


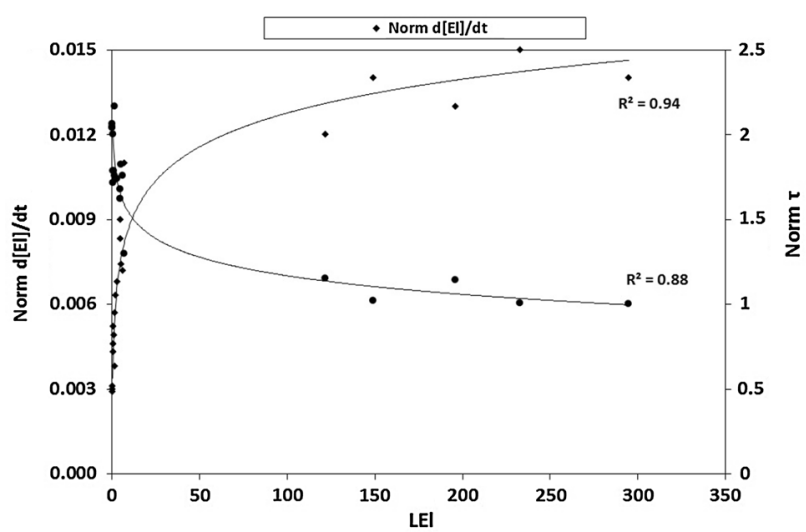

(a)

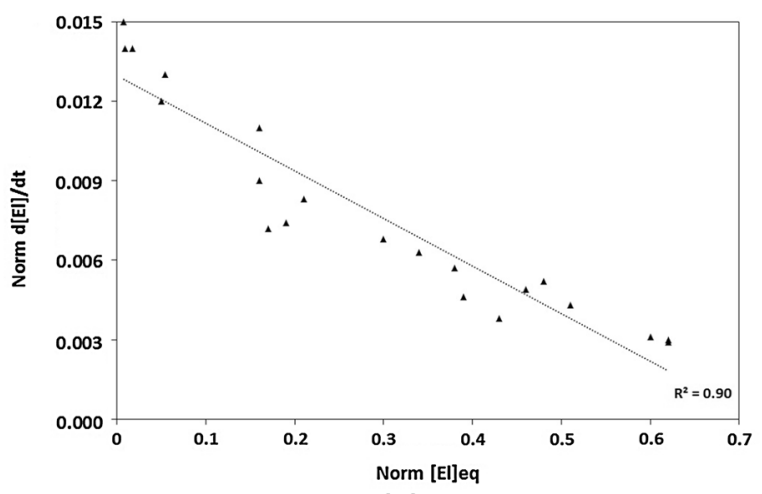

(b)

Fig. 9-(a) Normalized initial refining rate, Norm $\mathrm{d}[\mathrm{El}] / \mathrm{d} t$, and $\tau$ as a function of $L_{\mathrm{El}}$ and $(b)$ normalized initial refining rate as a function of normalized $[\mathrm{El}]_{\mathrm{eq}}$

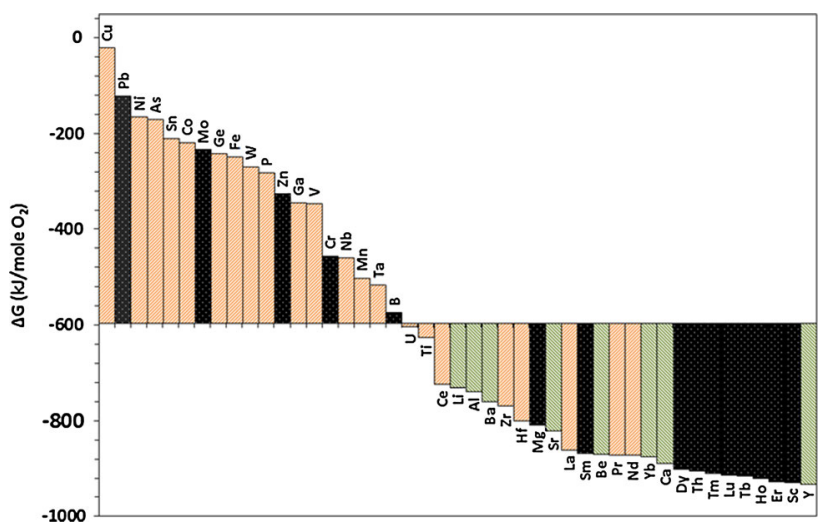

Fig. 10-The standard Gibbs free energies of oxide formation for the most stable oxide of each element, compared to that of $\mathrm{SiO}_{2}$ (represented by the y-axis). The black, speckled bars indicate that the oxide is evenly distributed between top and bottom slag. Orange, striped bars indicate a preference to go to top slag, while element oxides with green, striped bars primarily end up in the bottom slag.

bottom slag ratio (TBR) values, calculated from the experimental data of final slag compositions, are included in Table II and illustrated by the bar colors in Figure 10. Green, striped bars correspond to elements that are predominantly in the bottom slag (TBR $<0.5)$; black, speckled bars are elements that are approximately distributed $50 / 50$ between top and bottom slag (TBR 0.5 to 1.5), while orange, striped bars correspond to those elements mainly present in the top slag (TBR $>1.5)$. It is clear that all the elements with low $\tau$ and high $L_{\mathrm{El}}$ are mainly present in the bottom slag. This is consistent with the idea that this slag forms before the top slag. The top slag also contains more metallic silicon, which can contaminate the slag samples. A considerable amount of elements nobler than silicon found in the top slag is hence most likely a reflection of the high content of alloy in these samples.

\section{CONCLUSIONS}

This paper reports and discusses the refining characteristics of 45 impurity elements in the industrial oxidative ladle refining process for MG-Si. The time dependence of the elemental concentrations in the refining ladle has been experimentally determined for an industrial MG-Si process, using samples collected from 8 separate ladles. Three groups of element behavior were distinguished: elements readily refined in the ladle (21 elements: $\mathrm{Al}, \mathrm{Ba}, \mathrm{Be}, \mathrm{Ca}$, $\mathrm{Ce}, \mathrm{Dy}, \mathrm{Er}, \mathrm{Ho}, \mathrm{La}, \mathrm{Li}, \mathrm{Lu}, \mathrm{Mg}, \mathrm{Nd}, \mathrm{Pr}, \mathrm{Sm}, \mathrm{Sc}, \mathrm{Sr}, \mathrm{Tb}$, $\mathrm{Tm}, \mathrm{Yb}, \mathrm{Y})$, elements which do not respond to the refining process (19 elements: B, Co, Cr, Cu, Fe, Ge, Hf, Mn, Mo, $\mathrm{Nb}, \mathrm{Ni}, \mathrm{Pt}, \mathrm{P}, \mathrm{Ta}, \mathrm{Ti}, \mathrm{Th}, \mathrm{U}, \mathrm{V}, \mathrm{W}, \mathrm{Zr}$ ), and elements which are added by the flux material (5 elements: As, Ga, $\mathrm{Pb}, \mathrm{Sn}$, and $\mathrm{Zn}$ ). Among the readily refined elements, three kinetic groups are identified and linked to their position in the periodic system of the elements. The refining rates of elements are strongly correlated with element oxide basicities and correlated equilibrium distribution of the element between slag and metal. An empirical relation between the normalized $\tau$ and $L_{\mathrm{El}}$ for the current system was determined as

$$
\text { Norm } \tau=-0.16 \ln \left(L_{\mathrm{El}}\right)+1.9 \text {. }
$$

The refining trends are consistent and reproducible between ladles within the uncertainty limits for each element. While the numerical values of the kinetic parameters are process dependent and will vary between plants, the internal elemental ordering and trends are of general interest and may contribute to the development of thermo-kinetic databases for industrially relevant modeling purposes. We will in the continuation of the current work endeavor to establish more accurate refining models and data that can bring the description of current and future refining processes for silicon to a more advanced level.

\section{ACKNOWLEDGEMENTS}

The financing of this work was provided by the Norwegian Research Council and FFF (Norwegian Ferroalloy Producers Research Association) through the FUME Project (Fugitive emissions of Materials and Energy). We would like to express our appreciation to Elkem AS and to Norsk Elektro Optikk AS 
(NEO) for supporting these measurements with technical assistance, equipment, and more. Also, the contributions of Professor Emeritus T.A. Engh, Drs. K. Tang, and J.E. Olsen through in-depth discussions on fluid dynamics, kinetics, and thermodynamics are gratefully acknowledged.

\section{OPEN ACCESS}

This article is distributed under the terms of the Creative Commons Attribution License which permits any use, distribution, and reproduction in any medium, provided the original author(s) and the source are credited.

\section{REFERENCES}

1. A. Schei, J.K. Tuset, and H. Tveit: Production of High Silicon Alloys, 1st ed., TAPIR forlag, Trondheim, Norway, 1998.

2. R.J. Pomfret and P. Grieveson: Can. Metall. Q., 1983, vol. 22, pp. $287-99$.

3. E.R. Hurman: Mater. Manuf. Proces., 2008, vol. 23, pp. 769-76.

4. Y. Chung and A.W. Cramb: Metall. Mater. Trans. B, 2000, vol. 31B, pp. 957-71.

5. V.H. Hernandez, F. Reyes, J. Gutierrez, and G. Plascencia: Defect Diffus. Forum, 2008, vols. 273-276, pp. 491-99.

6. M.D. Johnston and M. Barati: Sol. Energy Mater. Sol. Cells, 2010, vol. 94, pp. 2085-90.

7. P. Bakke and O.S. Klevan: Process Technology Conference. Ladle Processing: Metallurgy and Operations, Orlando, FL, 1995.

8. T. Weiss and K. Schwerdtfeger: Metall. Mater. Trans. B, 1994, vol. $25 \mathrm{~B}$, pp. $497-504$.

9. A.T. Engh: Principles of Metal Refining, 1st ed., Oxford University Press, 1992.

10. J. Anglezio, C. Servant, and I. Ansara: CALPHAD, 1994, vol. 18, pp. 273-309.
11. M. Førde Møll: Ph.D. Thesis, Norwegian University of Science and Technology, Trondheim, Norway, 2014, ISBN 978-82-4714952-2.

12. H.M. Rong: Ph.D. Thesis, Norwegian University of Science and Technology, 1992, ISBN: 82-7119-435-6.

13. T. Margaria, M. Rebiere, F. Traversaz, and C. Dumay: in Silicon for the Chemical Industry, H.A. Øye, ed., Sandefjord, Norway, 1996, pp. 21-31.

14. J. Wu, W. Ma, B. Yang, Y. Dai, and K. Morita: Trans. Nonferrous Met. Soc. China, 2009, vol. 19, pp. 463-67.

15. L.A.V. Teixeira and K. Morita: ISIJ Int., 2009, vol. 49, pp. 78387.

16. T. Miki, K. Morita, and N. Sano: Metall. Mater. Trans. B, 1996, vol. 27B, pp. 927-41.

17. M.D. Johnston and M. Barati: J. Non-Cryst. Solids, 2011, vol. 357, pp. $970-75$.

18. L. Zhao, Z. Wang, Z. Guo, and C. Li: Trans. Non-ferrous Met. Soc. China, 2011, vol. 21, pp. 1185-92.

19. M.K. Naess, I. Kero, G. Tranell, K. Tang, and H. Tveit: JOM, 2014, vol. 66, pp. 1-12.

20. M.K. Naess, I. Kero, and G. Tranell: JOM, 2013, vol. 65, pp. $997-$ 1006.

21. M.K. Næss, G. Tranell, J.E. Olsen, N.E. Kamfjord, and K. Tang: Oxid. Met., 2012, vol. 78, pp. 239-51.

22. E.H. Myrhaug and H. Tveit: Iron \& Steel Society, AIST, Warrendale PA, 2000, pp. 591-604.

23. A. Ashrafian, S.T. Johansen, S. Gaal, B. Andresen, and O.S. Klevan: SINTEF/NTNU, Trondheim, Norway, 2008.

24. A. Ashrafian: SINTEF Materials and Chemistry, Trondheim, Norway, 2008

25. K. Nakajima and N. Usami: in Crystal Growth of Si for Solar Cells, Advances in Materials Research, vol. 14, Y. Kawazoe, ed., Springer Berlin Heidelberg, 2009.

26. L.K. Jakobssen: Ph.D. Thesis, Norwegian University of Science and Technology, Trondheim, Norway, 2013, ISBN (Print): 978-82471-4790-0 ISBN (El): 978-82-471-4791-7 ISSN: 1503-8181.

27. K. Tang: SINTEF Report No. F8532, Trondheim, 2007.

28. K. Tang, E.J. Ovrelid, and G. Tranell: Mater. Trans. JIM, 2009, vol. 50, pp. $1978-84$.

29. K. Tang: SINTEF Materials and Chemistry, Trondheim, Norway. 2013.

30. J. Duffy and M. Ingram: J. Non-Cryst. Solids, 1992, vol. 144, pp. 76-80. 